\title{
Landslide Inventory Mapping in the Fourteen Northern Provinces of Vietnam: Achievements and Difficulties
}

\author{
Le Quoc Hung, Nguyen Thi Hai Van, Pham Van Son, \\ Nguyen Hoang Ninh, Nguyen Tam, and Nguyen Thi Huyen
}

\begin{abstract}
The State-Funded Landslide Project (SFLP) is a national program to systematically assess landslide susceptibility, hazard and risk for all of prone areas in Vietnam. Under this SFLP, in the first phase of SFLP (2012-2014), activities of landslide inventory mapping were implemented over the fourteen Northern mountainous provinces. As the achievements, 10,149 historic landslides were mapped by field surveys and 9405 locations with landslide signs were interpreted from air-photos and analysis of 3D relief. Approximately $83 \%$ of the surveyed landslides locate in accessible areas, with small and medium dimensions and partly as a result of the slope cuts. About $76 \%$ of the interpreted landslides locate in inaccessible areas, and only $24 \%$ of the interpreted locate in accessible areas, of which $65 \%$ were found active landslides at the time of surveying, naturally occurred with large dimensions. However, the inventory exposes some major drawbacks: (1) The unavailability of multi-date air-photos; (2) The lack of human resources with enough experiences in image interpretation; (3) The difficulties of verifying the interpreted landslides, especially for the inaccessible sites; (4) Few or no sources of historic information due to the isolated sites or little memory of small or medium size events; (5) No updates developed by the surveyors after they finished their tasks. Those drawbacks can lead to the insufficiency of adequate data on the types, sizes and characteristics of the slope failures, especially the exact dates of occurrences. Despite of those difficulties, the achieved inventory database have been updated and then used as basic input for the susceptibility and hazard mapping as well as preliminary results of SFLP to inform the local authorities and communities about real situations of landslides in their areas.
\end{abstract}

\section{Keywords}

Landslide $・$ Inventory mapping $・$ Air-photo interpretation $・$ Field survey $\bullet$ Vietnam

\section{Introduction}

Vietnam is located in the tropical monsoon area, one of the five storm-prone areas with high rainfall in the Asia Pacific region. Three quarters of the mainland (or 37/63 provinces

L.Q. Hung $(\bowtie) \cdot$ N.T.H. Van · P.V. Son •

N.H. Ninh $\cdot$ N. Tam $\cdot$ N.T. Huyen

Vietnam Institute of Geosciences and Mineral Resources, 67 Chien Thang Street, Ha Dong District, Hanoi City, Vietnam e-mail: le.quoc.hung@vigmr.vn and cities) are hilly and mountainous regions, which have been recently playing a critical role in national socio-economic development. Over the past two decades, many areas in the mountains have attracted intensive flows of immigration to explore the natural resources. However, those regions are often threatened by a number of hazards, particularly landslides, causing losses and damages to people, properties, economics and environment (Hung et al. 2015). The problems of landsliding have been increasing under the impact of global climate change and expressed through many extreme rainfall events. They are also induced 
by human activities, such as deforestation, mining, slope-cutting for constructions of houses and roads. The incorporation of landslide mapping into regional and local land-use planning is an important measure to reduce the impact of landslides (Fell et al. 2008).

In Vietnam, landslide-related studies were carried out for a long time ago by means of traditional geological surveys, mainly by transect-walks. The investigations on landslide hazard and risk have evolved since the last two decades thank to the advancement of GIS and remote sensing technology (Hung et al. 2016). However, like in many other developing countries, as summarized by van Westen et al. (2006), there are many kinds of obstacles that make the execution of hazard risk zonation difficult in Vietnam. Most of projects on landslide mapping in Vietnam have been conducted at small scales (less than 1:100,000) in large regions (more than $1000 \mathrm{~km}^{2}$ ) (Hung et al. 2016). Several advanced-worldwide technologies for landslide zonation and warning at larger scales $(>1: 50,000)$ have been applied to several pilot areas, but not yet systematically adapted to the Vietnamese context (Hung et al. 2015). Those projects are often carried out by several organizations with different specialties for a number of purposes, and different criteria. Therefore, the results of previous works have not yet been integrated into one unified national database. Furthermore, the outcomes of those projects have not been transferred to the end-users, especially to the local communities and the national organizations for natural disaster prevention and control (Hung et al. 2015).

To overcome the above-mentioned limitations, the country needs a national program to systematically conduct landslide inventory mapping, assess landslide susceptibility, hazard and risk for all of prone areas. The programs should apply the advanced techniques for zoning and warning of landslides in mountainous areas in Vietnam and it is urgently needed in order to serve the operational effectiveness for prevention and mitigation of landslides in the context of climate change.

\section{The State-Funded Landslide Project (SFLP)}

The State-Funded Landslide Project (SFLP), namely "Investigation, assessment and warning zonation for landslides in the mountainous regions of Vietnam", was ratified by the Prime Minister of the Socialist Republic of Vietnam on 27 March 2012 under the Decision number 351/QĐ-TTg. The total budget for the whole Project, which sources from the Government of Vietnam, was approved by the Minister of Natural Resources and Environment on 29 August 2012 under the Decision number 1409/QD-BTNMT. This SFLP has been carried out by 10 organizations of Ministry of Natural Resources and Environment (MONRE) and
5 organizations of other ministries, in which the Vietnam Institute of Geoscience and Mineral Resources (VIGMR) is the coordinating organization. The project has been planned to be conducted in ten years from 2012 to 2020, and is divided into two phases: the first phase (2012-2015) and the second phase (2016-2020). The studied areas of this project consist of 37 mountainous provinces in the whole territory of Vietnam (Fig. 1).

The objectives of SFLP are: (1) to establish a standard national database on landslides and generation of landslide hazard maps at 1:50,000 scale for all mountainous provinces in Vietnam, and at 1:10,000 scale for specific areas in 17 Northern mountainous provinces; and (2) to design of an Early Warning System for landslides, and implementing that in a number of test areas. To obtain those two targets, the following main are proposed to execute in a period of 10 years:

1. Collecting, analyzing and compiling all data and documentation related to landslide hazard and risk;

2. Landslide inventory mapping, assessment of landslide causes and consequences, zoning of landslide susceptibility, hazard and risk for all mountainous regions of Vietnam;

3. Establishing a set of atlas of landslide warning zonation maps at scales of 1:50,000 for 37 mountainous provinces and at scales of 1:25,000-1:10,000 for high landslide hazard risk areas;

4. Establishing a scientific relevance for the setup of a landslide monitoring and early warning network in mountainous areas;

5. Pilot instrumentation for landslide monitoring at some landslide hotspots;

6. Developing a set of guidelines for the use of landslide databases, landslide hazard risk zonation maps, and landslide monitoring network;

7. Transferring of the Project results to the end-users to improve their capacity of landslides mitigation and management.

\section{Landslide Inventory Mapping Under the SFLP}

To fully carry out a landslide risk assessment, especially for analysis of landslide hazard, it is required to include information on historic landslides and involved losses. Therefore, landslide inventory mapping is the fundamental phase to evaluating landslide hazard and risk. Some countries in the world have been successful in establishing complete landslide inventories such as Hong Kong, Italy, Turkey, etc. (Guzzetti et al. 1994; Chau et al. 2004; Duman et al. 2005). Depending on the purpose and the available resources, landslide inventory maps are compiled at different scales using various techniques. 
Fig. 1 Map showing the administrative boundaries of 63 provinces in the mainland of

Vietnam, in which 37

mountainous provinces are studied areas of the State-Funded Landslide Project (SFLP)

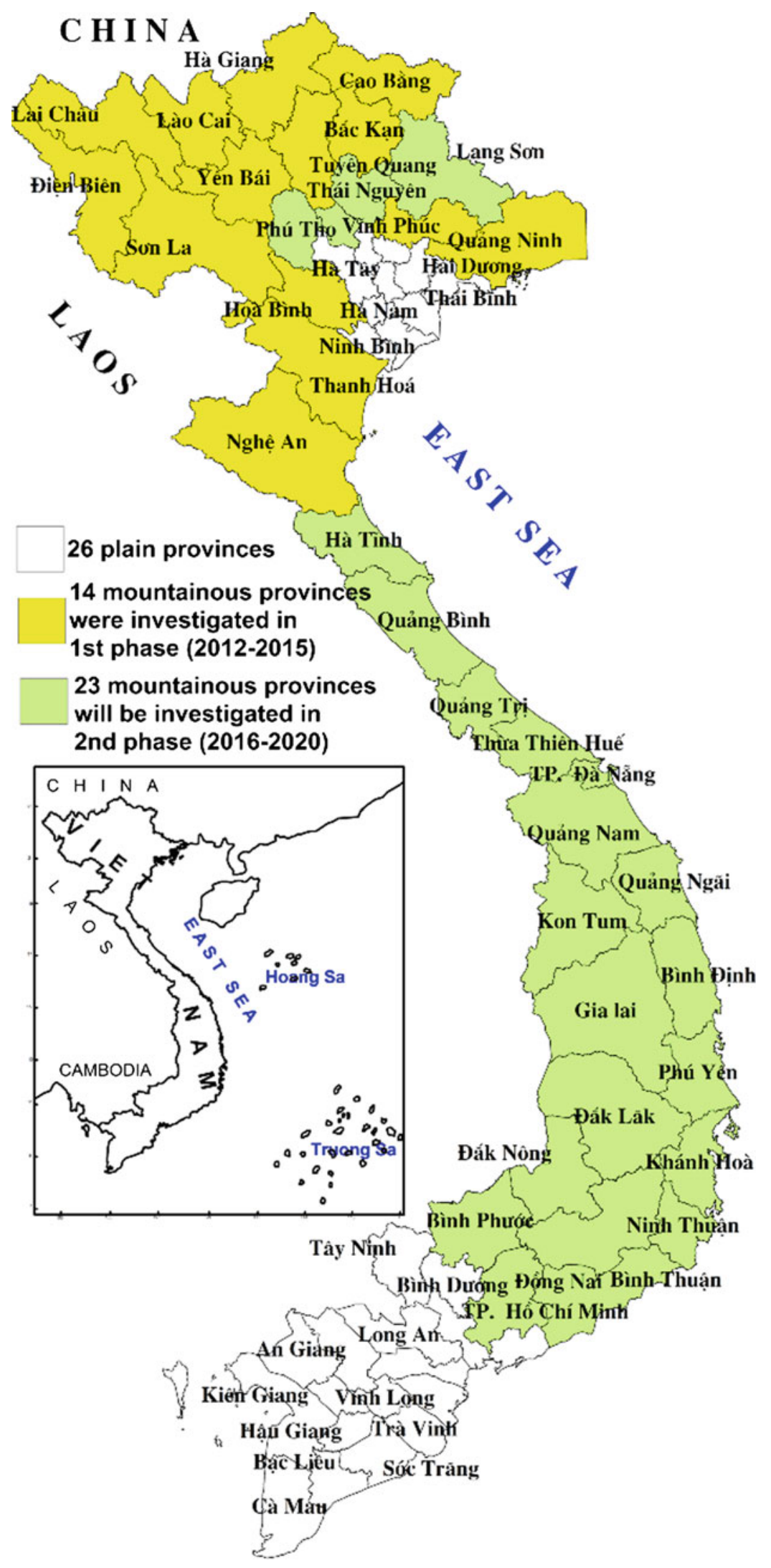


Under the SFLP, activities of landslide inventory mapping at 1:50,000 scale have been carried out since September 2012. In the first phase, mapping took place in the fourteen Northern mountainous provinces: Lai Chau, Dien Bien, Son La, Lao Cai, Yen Bai, Ha Giang, Tuyen Quang, Cao Bang, Bac Kan, Bac Giang, Quang Ninh, Hoa Binh, Thanh Hoa and Nghe An (Fig. 1). More than 500 staffs of 10 MONRE institutions were involved. Due to the difficulties in searching public media (such as journals, articles, newspapers, technical and scientific reports...) to collect historic information on past landslide events, the mapping activities of the SFLP mainly relied on the air-photo interpretation and field surveys (Fig. 2). The following tasks were carried out during the inventory mapping for each province:

1. Collection and review of journals, newspapers, technical/scientific reports/books and internal documents on landslides, other related geological hazards and controlling factors in the study area (topography, geology, meteorology, hydrology, historic landslides and rock landslide other geological disasters, remote sensing...);

2. Preparation for the field surveys: analysis of 3D relief based on 1:10,000 scale topographical maps; air-photo interpretation and analysis of other types of remote sensing images; and planning survey profiles over each investigated area.

3. Field surveys are based on landslide inventory forms: field measurements, interviews of local people and authorities.

4. Soil sampling and laboratory tests.

5. Compilation of landslide inventory maps per district at 1:50,000 scale.

6. Development of a national database on inventoried landslides and related geohazards.

7. Detail survey at some landslide hotspots that are proposed to set up a monitoring and early warning system.

8. Compilation of a provincial report, synthesis of the investigation results, and recommendations of prevention and mitigation measures (Fig. 3).

\section{Main Results of Landslide Inventory Mapping in the First Phase of the SFLP}

\section{The Landslide Inventory Database}

The most important result of the first phase of the SFLP is the national landslide inventory database that visually displays in a set of 142 landslide inventory maps at 1:50,000 scale for each districts of the fourteen investigated provinces. One example layout of those inventory maps is shown in Fig. 4. The resulting products are as follows:

- 9405 locations with landslide signs were delineated by interpretation of air-photos (captured in 2000) and analysis of 3D relief (interpolated from 1:10,000 topographic maps, which were constructed in 2000). 2218 locations ( $\sim 24 \%$ of the interpreted) were accessible in the field, of which 1446 locations (65\% of the accessible interpreted) were found active landslides at the time of surveying (Table 1).

- 10,149 historic landslides were mapped by field surveys; 5076 landslides are of small volume (less than $200 \mathrm{~m}^{3}$ ); 3346 landslides are of moderate volume $\left(200-1000 \mathrm{~m}^{3}\right)$; 1614 landslides are of large volume (1000-10,000 $\left.\mathrm{m}^{3}\right)$; 83 landslides are of very large volume $(10,000$ $100,000 \mathrm{~m}^{3}$ ), and 30 landslides are of extreme large volume (more than $100,000 \mathrm{~m}^{3}$ ) (Table 2).

The results show that approximately $83 \%$ of the surveyed landslides locate in accessible areas (along roads and inside/nearby residential areas) with the following characteristics: (a) having small and medium dimensions (from small to moderate volumes); (b) partly occurring as a result of the slope cuts; and (c) causing high losses in terms of economic values. On the contrary, about $76 \%$ of the interpreted landslides locate in inaccessible areas (remote areas/high mountains); only $24 \%$ of the interpreted locate in accessible areas, of which 65\% locations are active landslides with the following characteristics: (a) having large dimensions (from moderate to very large volumes); (b) naturally occurring; and (c) causing losses in terms of both economic values and human lives. The achieved inventory maps have been handed over to the above-mentioned provinces and involved organizations in order to inform the local authorities and communities about real situations, and improve the effectiveness of disaster prevention and mitigation in the investigated areas.

In addition, a part of the database has been published on the website as a WebGIS on landslides (http://www. canhbaotruotlo.vn/). This online spatial database includes maps of landslide inventory and controlling factors at 1:50,000 scale for all the investigated provinces (Fig. 3). This system has been used as a simple tool for updating historic events as well as broadcasting urgent information through the Web browsers. It is also considered as one of national interactive interfaces among scientists, managers and local communities for landslide early warning; especially for fulfilling the missing information of historic 

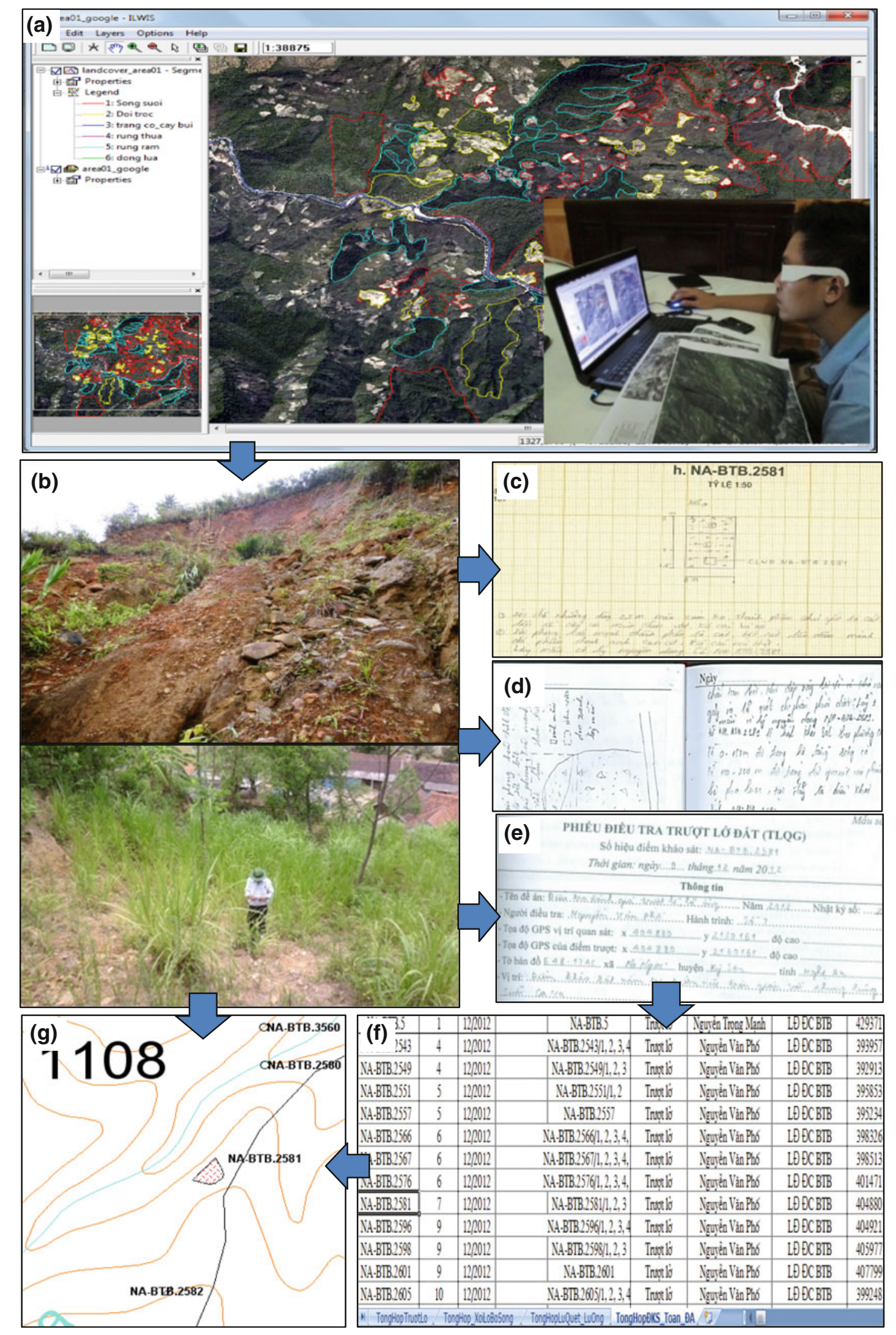

Fig. 2 Main techniques for landslide inventory mapping in Vietnam under the State-Funded Landslide Project include: a air-photo interpretation and 3D relief analysis; $\mathbf{b}$ field survey; c soil description sheet; $\mathbf{d}$ field note; e inventory form; f landslide database; and $\mathbf{g}$ GIS mapping 


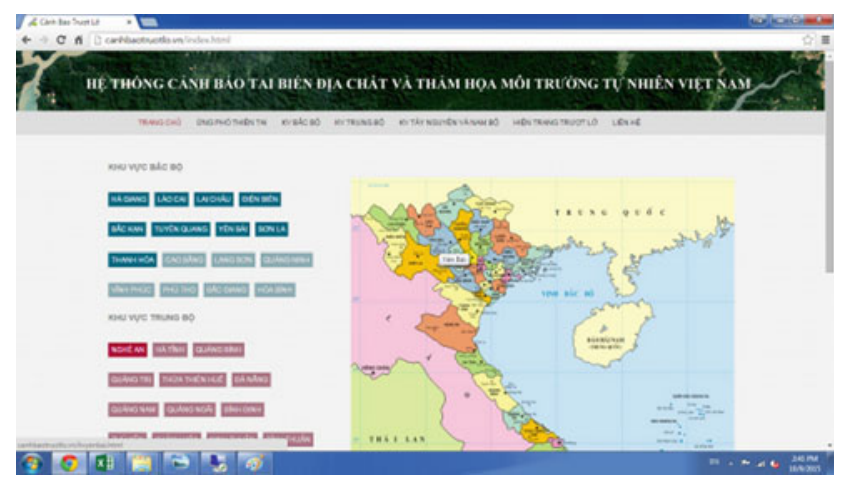

Fig. 3 Main interface of the WebGIS on landslides as one of main achievement of the SFLP in the first phase

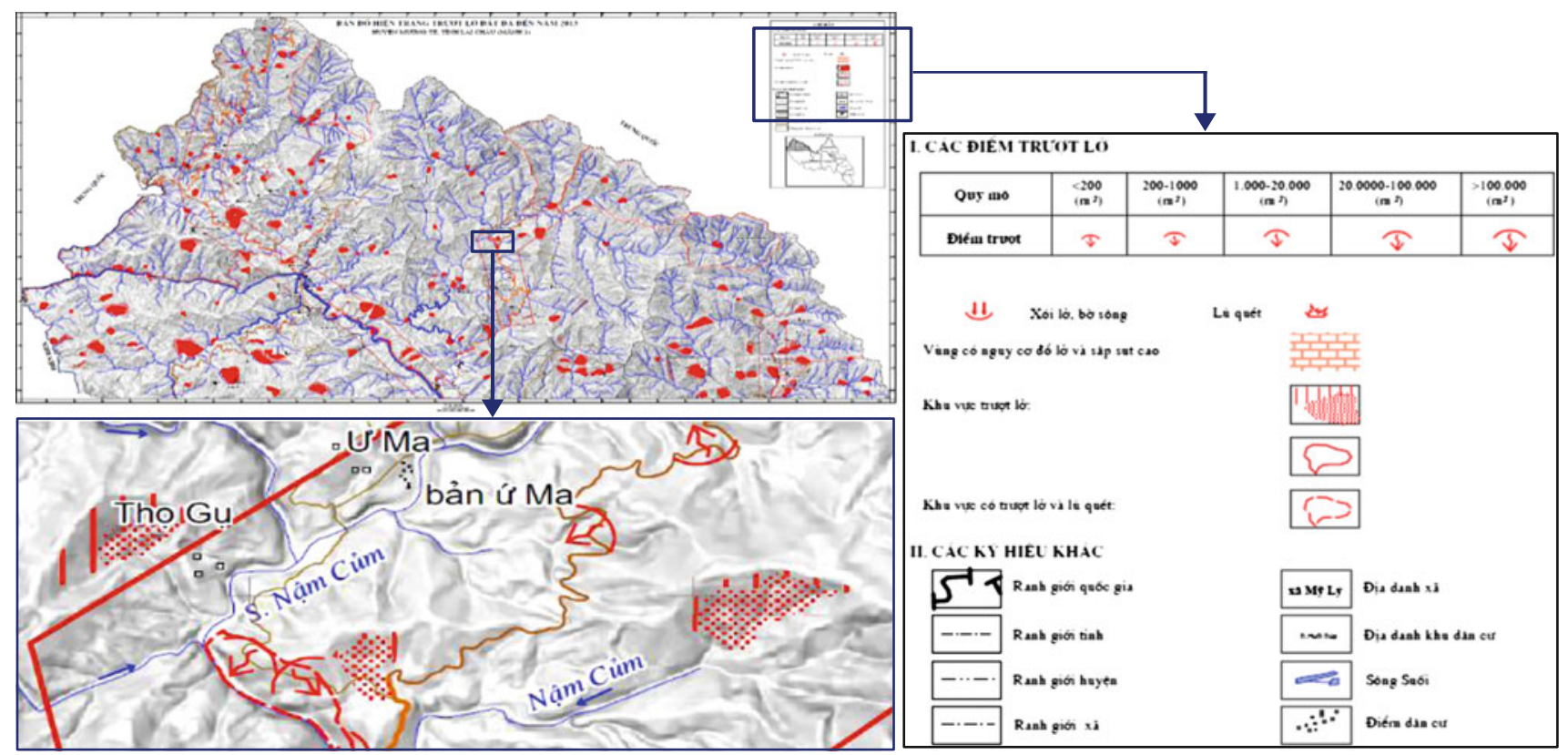

Fig. 4 An example layout of a landslide inventory map constructed at 1:50,000 scale for each district and then handed over to the end-users in mountainous provinces in Vietnam

landslides and promptly describe the new landslides or provide warning. All provided information will be used to inform the local authorities and communities about real situations, and improve the capacity of scientific research as well as the effectiveness of disaster prevention and mitigation in the mountainous areas of Vietnam.

\section{The Promulgation of a Field Guidelines for Landslide Inventory Mapping at 1:50,000 Scale in Vietnam}

Another achievement of the landslide inventory mapping in the first phase of the SFLP was the establishment of field 
Table 1 Summary of air-photo interpretation results for the landslide inventory mapping in the 14 mountainous provinces of Vietnam

Table 2 Summary of field-surveyed results for the landslide inventory mapping in the 14 mountainous provinces of Vietnam

\begin{tabular}{|c|c|c|c|c|}
\hline Provinces & $\begin{array}{l}\text { Number of } \\
\text { interpreted } \\
\text { landslides }\end{array}$ & $\begin{array}{l}\text { Number of accessible } \\
\text { interpreted landslides }\end{array}$ & $\begin{array}{l}\text { Number of active landslides at } \\
\text { the accessible interpreted }\end{array}$ & $\begin{array}{l}\% \text { verified } \\
\text { landslides }\end{array}$ \\
\hline Lai Chau & 905 & 372 & 229 & 62 \\
\hline $\begin{array}{l}\text { Dien } \\
\text { Bien }\end{array}$ & 748 & 172 & 92 & 53 \\
\hline Son La & 1791 & 255 & 181 & 71 \\
\hline Lao Cai & 551 & 152 & 98 & 64 \\
\hline Yen Bai & 708 & 251 & 183 & 73 \\
\hline Ha Giang & 1161 & 112 & 68 & 61 \\
\hline $\begin{array}{l}\text { Tuyen } \\
\text { Quang }\end{array}$ & 266 & 84 & 35 & 42 \\
\hline $\begin{array}{l}\text { Cao } \\
\text { Bang }\end{array}$ & 268 & 124 & 65 & 52 \\
\hline Bac Kan & 317 & 150 & 90 & 60 \\
\hline $\begin{array}{l}\text { Bac } \\
\text { Giang }\end{array}$ & 35 & 4 & 1 & 25 \\
\hline $\begin{array}{l}\text { Quang } \\
\text { Ninh }\end{array}$ & 46 & 30 & 8 & 27 \\
\hline Hoa Binh & 68 & 45 & 20 & 44 \\
\hline $\begin{array}{l}\text { Thanh } \\
\text { Hoa }\end{array}$ & 1194 & 87 & 67 & 77 \\
\hline Nghe An & 1347 & 380 & 309 & 81 \\
\hline Total & 9405 & 2218 & 1446 & \\
\hline$\%$ & & 24 & & 65 \\
\hline
\end{tabular}

\begin{tabular}{|c|c|c|c|c|c|c|c|}
\hline $\mathrm{Nr}$. & Provinces & $\begin{array}{l}\text { Sum of } \\
\text { surveyed } \\
\text { landslides }\end{array}$ & $\begin{array}{l}\text { Small } \\
\text { volume } \\
\left(<200 \mathrm{~m}^{3}\right)\end{array}$ & $\begin{array}{l}\text { Moderate } \\
\text { volume } \\
(200- \\
\left.1000 \mathrm{~m}^{3}\right)\end{array}$ & $\begin{array}{l}\text { Large } \\
\text { volume } \\
(1000- \\
\left.10,000 \mathrm{~m}^{3}\right)\end{array}$ & $\begin{array}{l}\text { Very large } \\
\text { volume } \\
(10,000- \\
\left.100,000 \mathrm{~m}^{3}\right)\end{array}$ & $\begin{array}{l}\text { Extremely } \\
\text { large volume } \\
\left(>100,000 \mathrm{~m}^{3}\right)\end{array}$ \\
\hline 1 & Lai Châu & 970 & 337 & 325 & 280 & 18 & 10 \\
\hline 2 & Điện Biên & 673 & 335 & 181 & 139 & 12 & 6 \\
\hline 3 & Sơn La & 1694 & 795 & 622 & 266 & 11 & \\
\hline 4 & Lào Cai & 534 & 316 & 162 & 53 & 3 & \\
\hline 5 & Yên Bái & 1165 & 580 & 385 & 187 & 9 & 4 \\
\hline 6 & Hà Giang & 963 & 519 & 289 & 150 & 2 & 3 \\
\hline 7 & $\begin{array}{l}\text { Tuyên } \\
\text { Quang }\end{array}$ & 246 & 151 & 94 & 1 & & \\
\hline 8 & Cao Bằng & 88 & 21 & 42 & 25 & & \\
\hline 9 & Bắc Kạn & 720 & 305 & 282 & 123 & 9 & 1 \\
\hline 10 & Bắc Giang & 302 & 192 & 94 & 16 & & \\
\hline 11 & $\begin{array}{l}\text { Quảng } \\
\text { Ninh }\end{array}$ & 374 & 162 & 141 & 67 & 4 & \\
\hline 12 & Hòa Bình & 184 & 69 & 81 & 34 & & \\
\hline 13 & Thanh Hóa & 938 & 630 & 223 & 78 & 7 & \\
\hline \multirow[t]{3}{*}{14} & Nghệ An & 1298 & 664 & 425 & 195 & 8 & 6 \\
\hline & Total & 10,149 & 5076 & 3346 & 1614 & 83 & 30 \\
\hline & $\begin{array}{l}\text { Percentage } \\
(\%)\end{array}$ & 100 & 50.01 & 32.97 & 15.90 & 0.82 & 0.30 \\
\hline
\end{tabular}


guidelines for landslide inventory mapping at 1:50,000 scale. It was developed by SFLP's key staffs and other international experts, then promulgated by MONRE on the 20th of November, 2013 under the Decision number 2321/QĐ-BTNMT (MONRE 2013). These guidelines comprise of 4 chapters, 22 main clauses and 11 annexes. The most important contribution of these guidelines is the development of a landslide inventory form for field surveys. All members of the staff from different organizations and background followed these guidelines.

\section{Major Difficulties in Landslide Inventory Mapping During the First Phase}

\section{Lack of Multi-date Data}

There are insufficiency of multi-date air-photos as well as base maps for developing the inventory. In the beginning of the SFLP, several base maps (e.g., topography, land cover, forest, road systems, geomorphology, ect. at 1:200,000 $1: 10,000$ scales) were collected from other institutions. However, most of them were problematic due to the overlap of digitization, incorrect attributes, etc. In addition, some types of satellite images of low resolution (e.g., Landsat TM/ETM, SPOT) were available at VIGMR, but they required experienced experts on image processing to detect old landslides. Processing those images would require more time, budget and human resources. Therefore, only topographical maps at 1:10,000 scale and air-photos captured in 2000 were used in the project.

\section{Lack of Human Resources with Experiences}

The staffs involved in developing the landslide inventory mapping mainly came from geological institutions and had little skills on landslide investigation; particularly, they were not familiar with air-photo processing. At the beginning of the first phase, only few members of the staff could identified historic landslides on the aerial photographs; many others needed training and practice for image interpretation. At the end of the inventory phase, there were incomplete landslide records due to the lack of skills and experience of the field surveyors.

\section{Insufficient Measures for Field-Checks}

A lot of landslides were found along the road cuts, in which landslide deposits are usually removed very soon after failure. Furthermore, many slides were not visible or were missed in the interpretation of air-photos because of their small sizes, the coverage of tree plantation, removal of soil masses or new build-ups after the events. Especially in the areas with fast development of constructions, the trace of a failure can be replaced by a new or larger cut or new buildings in a short time right after the event. Information on historic landslides in the isolated places as well as in the crowded areas are always difficult to recover from the local people. Therefore, it is difficult to validate the interpreted landslides in the field.

\section{Little Sources of Archived Information on Historic Landslides}

In Vietnam, there is a top-down structured system for the disaster management, namely the "Department of Natural Disaster Prevention and Control". Those organizations are in charge of collecting historic/urgent information before/during and after disastrous events. All the collected information are timely/periodical reported to the higher level of the management system as well as broadcasted by public media. However, the collected information is not yet sufficient because:

- The content of their reports mostly contains the summary of the events that are always related to the typhoons, heavy rains, and floods.

- Landslide is often mentioned as a concatenated event or typhoon/rain-induced disaster; or as a single event if it did not happen during a typhoon/heavy rain or caused serious impacts to a particular province or region or the whole country.

- The reports are kept in a short time without archiving all of important data in a good database.

\section{Conclusions}

Landslide inventory mapping is a crucial step for landslide research. During the first phase of the project (20122015), more than 9400 locations with landslide signs were mapped by means of air-photo interpretation and 3D-relief analysis. About 24\% of those interpreted landslides were accessible in the field, of which $65 \%$ were found active landslides and 35\% were not able to trace slope failure. The most important achievement is the development of the database comprising the historic landslide inventory, which includes 10,149 landslides. Out of the total, $50 \%$ are of small volume, $33 \%$ are moderate, $16 \%$ are large, and $0.30 \%$ are of extreme large volume. The produced data has been printed on maps as well as published on a national WebGIS on landslides. 
Along with those above-mentioned achievements in the first phase of the project, the landslide inventory mapping has exposed the following major drawbacks: (1) The unavailability of multi-date air photos; (2) The lack of human resources with enough experiences in image interpretation; (3) The difficulties of verifying the interpreted landslides, especially for the inaccessible sites; (4) Few or no sources of historic information due to the isolated sites or little memory of small or medium size events; (5) No updates developed by the surveyors after they finished their tasks. Those drawbacks can lead to the insufficiency of adequate data on the types, sizes and characteristics of the slope failures, especially the exact dates of occurrences. Therefore, it would be difficult to correlate the landslide with a triggering event as different landslides have different meteorological triggers.

To overcome the above-mentioned obstacles in the second phase, some of the recommendations included: (1) Making the most advantage of available Google Earth, satellite and radar images; (2) Providing and/or participating in the training courses for image processing and interpretation as well as for improving their capacity of inventory mapping; (3) Involving the local communities in field surveys; (4) Upgrading and maintaining the online spatial database - WebGIS on landslides, and training the local authorities and people to use the WebGIS for validating inventoried landslides, as well as for updating the historic and recent landslides.

Despite of many obstacles, a set of landslide inventory maps at 1:50,000 scale for the fourteen mountainous provinces have been handed over to the local authorities and officers of the Department of Natural Disaster Prevention and Control. The published maps have been used by the local people and officers as a preliminary early warning on landslide sites. The landslide database and digital maps and in Argus, MapInfo and Web-GIS have been used by both local and central authorities and officers as a tool for promptly updating and warning about the occurrence of new landslides reported and included in the database by the local people.

Acknowledgements The authors would like to thank all the members of the staff of VIGMR and to the other involved institutions under the
MONRE, for their contributions to the SFLP. The authors also credit all local people and authorities for their support and international landslide experts for their guidance to complete the mapping activities.

\section{References}

Chau KT, Sze YL et al (2004) Landslide hazard analysis for Hong Kong using landslide inventory and GIS. Comput Geosci 30 (4):429-443

Duman TY, Can T et al (2005) Landslide inventory of northwestern Anatolia, Turkey. Eng Geol 77(1-2):99-114

Fell R, Corominas J et al (2008) Guidelines for landslide susceptibility, hazard and risk zoning for land use planning. Eng Geol 102(34):85-98

Guzzetti F, Cardinali M, Reichenbach P (1994) The AVI Project: a bibliographical and archive inventory of landslides and floods in Italy. Environ Manage 18(4):623-633

Hung LQ, Van NTH, Tam N et al (2015) Overview of landslide inventory mapping at 1:50,000 scale in the mountainous areas of Vietnam (2012-2014). J Geol Min Resour 11:154-160 (in Vietnamese)

Hung LQ, Van NTH, Duc DM, Ha LTC, Son PV, Khanh NH, Binh LT (2016) Landslide susceptibility mapping by combining the analytical hierarchy process and weighted linear combination methods: a case study in the upper Lo River catchment (Vietnam). Landslides 13(5):1285-1301

Khien NX, Hung LQ et al (2012) Report of project "Assessment of status geohazards in four mountainous provinces in North of Viet Nam: Ha Giang, Bac Kan, Cao Bang, Tuyen Quang. Identification of sources, prediction and propose preventive measures and consequences mitigation" sponsored by Ministry of Natural Resources and Environment. Center for Information and Archives of Geology, Hanoi, 318 p (in Vietnamese)

MONRE (2013) Decision No.2321/QĐ-BTNMT issued on 20 November, 2013 on "Technical guidelines for landslide inventory mapping at 1:50,000 scale in the mountainous areas of Vietnam". Vietnam Ministry of Natural Resources and Environment, Hanoi, 68 p (in Vietnamese)

Thinh DV et al (2004) Report of project "Geohazard surveys in the Northwestern mountainous regions of Vietnam" sponsored by Ministry of Industry. Center for Information and Archives of Geology, Hanoi 305 p (in Vietnamese)

van Westen CJ, van Asch TWJ et al (2006) Landslide hazard and risk zonation: why is it still so difficult? Bull Eng Geol Environ: Off J Int Assoc Eng Geol Environ: IAEG 65(2):67-184

Varnes DJ (1978) Slope movement types and processes. In: Schuster RL, Krizek, RJ (eds) Landslides: analysis and control. Transportation Research Board, National Academy Press, Special report 176, National Research Council, Washington, D.C., pp 11-33 
Open Access This chapter is licensed under the terms of the Creative Commons Attribution 4.0 International License (http:// creativecommons.org/licenses/by/4.0/), which permits use, sharing, adaptation, distribution and reproduction in any medium or format, as long as you give appropriate credit to the original author(s) and the source, provide a link to the Creative Commons license and indicate if changes were made.
The images or other third party material in this chapter are included in the chapter's Creative Commons license, unless indicated otherwise in a credit line to the material. If material is not included in the chapter's Creative Commons license and your intended use is not permitted by statutory regulation or exceeds the permitted use, you will need to obtain permission directly from the copyright holder. 